\title{
Bullying e agressão: Estudo dos preditores no contexto de programa de intervenção da violência escolar
}

\author{
Patrícia Gouveia ${ }^{12}$, Isabel Leal ${ }^{1} \&$ Jorge Cardoso ${ }^{2}$ \\ ${ }^{1}$ William James Center for Research, ISPA-Instituto Universitário, Lisboa \\ ${ }^{2}$ Centro de Investigação Interdisciplinar Egas Moniz - ISCSEM, Monte de Caparica
}

\begin{abstract}
Resumo: Os processos interativos na escola, pares e contextos familiares dos adolescentes apresentam um peso considerável no estudo dos fatores de risco e protetores associados ao desenvolvimento de comportamentos agressivos. Atendendo a esta premissa, pretendemos analisar a relação entre a perceção que os jovens têm do seu suporte social e do ambiente escolar e o desenvolvimento das diferentes formas e funções de comportamentos agressivos. Participaram no estudo 851 adolescentes, com idades compreendidas entre os 11 e os 19 anos, a frequentar o ensino básico e secundário. Recorrendo a regressões hierárquicas, obtivemos 2 modelos explicativos dos fatores de risco e protetores da agressão direta reativa, agressão relacional reativa, agressão direta instrumental e agressão relacional instrumental. Os resultados revelam interessantes padrões de risco e proteção para cada um dos subtipos de comportamento agressivo. As relações familiares e o ambiente escolar são preditores-chave para esta amostra, quer de risco, quer de proteção.
\end{abstract}

Palavras-chave: Agressão Reativa; Agressão Instrumental; Adolescentes; Teoria dos Sistemas Ecológicos; Fatores de Risco e Protetores.

Bullying and aggression: A study of the predictors in the context of a school violence intervention program: The adolescents interactive processes at school, peers and family contexts presents considerable weight in the study of risk and protective factors associated with the development of aggressive behavior. Given this premise we intend to analyze the relationship between the perception that young people have of their social support and the school climate and the development of different forms and functions of aggressive behavior. Participated in the study 851 adolescents aged between 11 and 19 years, attending elementary and high school grades. Using hierarchical regression, 2 models are presented that capture significant risk and protective factors for reactive overt aggression, reactive relacional aggression, instrumental overt aggression, and instrumental relacional aggression. Results reveal several insteresting patterns of risk and protection for each subtipe of aggressive behavior. Relationships with parents and school climate are key predictors for this sample, representing both risk and protection.

Keywords: Reactive Aggression; Instrumental Aggression; Adolescents; Ecological Sistems Theory; Risk and Protection Factors.

"Todo o comportamento de bullying é agressivo, mas nem todo o comportamento agressivo é bullying" (Rodkin, Espelage, \& Hanish, 2015, p. 314). A sobreposição entre comportamento agressivo e bullying conduz à necessidade de uma distinção clara entre estes dois constructos. Por um lado, perceber o que torna o bullying único e distinto do comportamento agressivo em geral e, por outro, de que forma esta distinção ganha relevância no delineamento de programas interventivos e nas suas metodologias (Rodkin et al., 2015).

Entenda-se por agressão um comportamento indesejável e inerente ao ser humano, (Hawley \& Vaughn, 2003), de carácter biológico adaptativo, i.e., um comportamento reativo desencadeado por situações percecionadas como ameaçadoras (Palacios \& Berger, 2016). Do ponto de vista do ajustamento social, supõe ações ou comportamentos (externos) que têm como intenção magoar outra(s) pessoa(s), implicando pelo menos, dois indivíduos (Bushman \& Huesmann, 2010).

Considerado um subtipo de agressão (Espelage \& Swearer, 2003), o bullying assemelha-se a esta do ponto de vista comportamental (i.e., ações físicas ou relacionais), mas distingue-se da primeira pela sua natureza intencional e abusiva (Rodkin et al., 2015). 0 bullying é considerado uma forma de agressão interpessoal complexa, que apresenta distintas formas e funções e que se manifesta por diferentes

${ }^{1}$ Endereço para correspondência: WJCR (William James Center for Research), ISPA: Instituto Universitário, Rua Jardim do Tabaco, 34,1149 041 Lisboa, Portugal. E-mail: pgouveia@ispa.pt 
padrões relacionais (Swearer \& Hymel, 2015). A sua definição compreende três condições fundamentais associadas ao comportamento agressivo: 1) o padrão repetido da intimidação física ou psicológica ao longo do tempo; 2) a intencionalidade desse comportamento (provocar mal-estar e ganhar controlo sobre outra pessoa) e, 3) o desequilíbrio de poder físico ou psicológico entre o perpetrador e a vítima (sendo o bully percecionado como o mais forte) (Olweus, 1993).

De relevo na explicação dos padrões cognitivos implicados no desenvolvimento e manutenção dos comportamentos agressivos, entre os quais aqueles que configuram práticas de bullying, o modelo de processamento da informação social (Crick \& Dodge, 1994) preconiza que as atitudes das crianças (prósociais e agressivas) são produtos das suas cognições sociais, e identifica seis etapas primárias subjacentes ao processo de cognição social das crianças: codificação de sinais sociais, interpretação desses sinais, seleção de objetivo, formulação de resposta, avaliação e ação (Crick \& Dodge, 1994). Assim, as crianças com comportamento agressivo, incluindo o bullying, apresentariam falhas ao longo destas fases de processamento, cuja análise permite a sua categorização. De acordo com Griffin e Gross (2004) o bullying e os comportamentos agressivos podem ser categorizados como reativo - reação defensiva a um estímulo percecionado como ameaçador, que denota zanga ou raiva visível; proativo ou instrumental comportamento agressivo deliberado que visa atingir objetivos instrumentais e onde a agressão é entendida como um meio efetivo para receber recompensas ou solucionar conflitos; direto - agressão direta (e.g., pontapés, socos, ofensas verbais) dirigida a um individuo ou grupo, e relacional comportamento que envolve a exclusão de alguém de um grupo social, espalhar rumores ou humilhar outro indivíduo num contexto social. A categorização da agressão tem sido ainda associada às variantes da sintomatologia psicopatológica, surgindo a agressão direta, mais relacionada com os comportamentos externalizantes (e.g., problemas de conduta) e a agressão indireta com os problemas internalizantes (e.g., ansiedade e depressão) (Card, Stucky, Sawalani, \& Little, 2008).

No que concerne às funções da agressão, foco primário deste estudo, a agressão reativa está associada à atribuição de uma intenção hostil ao comportamento dos pares em situações sociais ambíguas, a dificuldades na regulação emocional, a sintomas internalizantes (e.g., depressão) e a rejeição pelos pares (Crick \& Dodge, 1996; Schwartz, McFadyen-Ketchum, Dodge, Pettit, \& Bates, 1998; Xu \& Zhang, 2008). A agressão proativa, relacionada com uma avaliação positiva da agressão e das suas possíveis consequências (Crick \& Dodge, 1996; Xu \& Zhang, 2008), está associada a comportamento antissocial a longo prazo (Fite, Rathert, Colder, Lochman, \& Wells, 2012; Vitaro \& Brendgen, 2011). Contudo, a agressão proativa também tem sido relacionada com liderança e popularidade, sugerindo que esta é influenciada pelas relações pré-estabelecidas com os pares (Sijtsema et al., 2010). Assim, enquanto uns jovens são mais eficazes no uso da agressão para obtenção de poder, ascendendo na hierarquia do grupo de pares, outros falham (Rodkin et al., 2015). Salienta-se, contudo, que apesar da agressão e do bullying se encontrem associados com a popularidade, parecem implicar diferentes configurações interpessoais. No que concerne à relação com os pares, o bullying assenta em relações abusivas. Assim sendo, a sua função adaptativa e consequentemente a sensibilidade à influência dos pares, pode não ser direta (Palacios \& Berger, 2016).

A perspetiva orientada para a pessoa permite distinguir os padrões de bullying mais ou menos adaptativos. De acordo com Olweus (1978) existem dois padrões distintos: o dos bullies, i.e., crianças que perpetram bullying e os dos bullies vítimas, i.e., crianças que perpetram e são vítimas de agressão. Enquanto que os bullies são mais funcionais e mais propensos a recorrer a agressão proativa, os bullies vítimas estão mais propensos a agressão reativa, evidenciando um padrão de risco mais problemático. Farmer et al. (2010) apresentam uma abordagem relacional para explicar o comportamento de bullying, inferindo que existem dois "mundos sociais" de bullying, a integração e a marginalização social. Os bullies socialmente integrados, que utilizam a agressão para controlo e fazem recurso a um tipo de agressão mais instrumental e os bullies marginalizados, que recorrem a um tipo de agressão reativa, nomeadamente contra o sistema social que os segrega e os coloca à margem. Os primeiros apresentam um bom ajustamento social, enquanto que os segundos apresentam um pobre ajustamento social e são normalmente identificados como alunos de risco (Cook, Williams, Guerra, Kim, \& Sadek, 2010). Contudo, ressalva-se a necessidade de mais estudos que permitam inferir se o comportamento de bullying é melhor determinado pelas categorias de bully e bully vítima ou socialmente integrado e marginalizado (Rodkin et al., 2015).

Para além dos modelos explicativos orientados para a pessoa ou para a relação com o grupo, existem outros orientados para a relação pessoa-grupo. Segundo o modelo de dissimilaridade pessoagrupo (Wright, Giammarino, \& Parad, 1986), o comportamento pró-social encontra-se associado a aceitação pelos pares dentro do grupo. Contudo, os comportamentos negativos, entre os quais a agressão, apenas se associam a rejeição pelos pares quando a pessoa não se enquadra no perfil do grupo. Assim, as normas de determinado grupo, são entendidas como moderadoras da relação entre o comportamento do 
indivíduo e o estatuto social que este adquire no grupo de pares. Este modelo, aplicado ao comportamento de bullying por Sentse, Scholte, Salmivalli e Voeten (2007), explica o motivo pelo qual a forma instrumental da agressão se encontra muitas vezes associada a comportamento de bullying. Os resultados de Sentse et al. (2007) indicam que em salas de aula onde existam elevados níveis de bullying, os bullies são preferidos pelos colegas de turma, gozando de um estatuto de popularidade dentro do grupo de pares. No entanto, de acordo com esta teoria, uma vez que o estatuto social é específico do contexto, o estatuto de popularidade entre os colegas de turma não descarta necessariamente o risco de desajustamento psicossocial. Noutros contextos (e.g., bairro, família), essas crianças podem manifestar sinais de desajustamento.

\section{BULLYING E AGRESSÃO: FATORES DE RISCO E PROTETORES}

Importante no delineamento de programas preventivos e interventivos é o estudo dos fatores de risco e protetores associados ao desenvolvimento de comportamentos agressivos no geral (e.g., Williford \& DePaolis, 2012), ou de bullying em particular (consultar a revisão sistemática de Álvarez-García, García, \& Núñez, 2015). Aquilo que os estudos apontam é que tal como existe uma sobreposição entre os mecanismos e as a categorias da agressão e o bullying, também os antecedentes explicativos evidenciam semelhanças (Rodkin et al., 2015).

Primeiramente, entenda-se por fator de risco "qualquer influência que intensifique a hipótese de magoar ou, mais especificamente, influências que incrementam a probabilidade de início, progressão para um estado mais grave ou manutenção de uma condição problemática" (Fraser, Kirby, \& Smokowski, 2004, p.14). No que concerne aos fatores protetores, não encontramos uma definição clara e consistente. Numa perspetiva muito sintética, Fraser et al. (2004, p.28) referem que estes fatores dizem respeito aos "recursos internos e externos que modificam o risco".

A compreensão dos fatores preditores da agressão ou do bullying em contexto escolar pressupõe, assim, uma análise detalhada da complexidade de relações entre o indivíduo e o ambiente que o rodeia (Hong \& Espelage, 2012; Williford \& DePaolis, 2012). Este quadro de análise é facilitado em modelos sistémicos de que é exemplo o modelo ecológico de Bronfenbrenner, que tem sido utilizado para conceptualizar e organizar os aspetos associados a qualquer problema social complexo (Copeland-Linder, Lambert, \& Ialongo, 2010; Moscardino, Fabia, Capello, \& Altoe, 2010), tal como a agressão e o bullying (Hong \& Espelage, 2012; Moretti, Catchpole, \& Odgers, 2005; Williford \& DePaolis, 2012). Recorrendo aos níveis individual e do micro-sistema, preconizados no modelo ecológico de Bronfenbrenner (1994), apresentamos de seguida a análise dos fatores preditores mais apontados, tanto na literatura da agressão, como na do bullying.

\section{Influências do nível individual Género}

No que concerne às diferenças de género, a literatura não se revela consensual, quer para a agressão, quer para o bullying. A maioria dos estudos aponta a forma de agressão direta, ou as formas diretas de bullying, como mais prevalentes nos rapazes (Hawley, Little, \& Card, 2008; Moretti, Holland, \& McKay, 2001; Olweus, 1993; Varjas, Henrich, \& Meyers, 2009), e a agressão relacional ou o bullying indireto, como mais frequente nas raparigas (Prinstein, Boergers, \& Venberg, 2001; Varjas et al., 2009). Outros trabalhos documentam níveis de agressividade direta ou relacional mais elevados nos rapazes, indicando que estes apresentam uma maior propensão a envolverem-se em comportamentos agressivos (Álvarez-Garcia et al., 2015; Chang et al., 2013; Prodocimo, Cerezo, \& Arense, 2014). No entanto, existem estudos que não apresentam quaisquer diferenças em função desta variável (Loflin \& Barry, 2016; Espegale, Polanin, \& Low, 2014). Deste modo, exige-se algum cuidado na formulação de conclusões acerca das diferenças de género, pois a tendência é para acreditar que poderá não constituir um preditor significativo de comportamento agressivo ou de bullying (Espelage, Mebane, \& Swearer, 2004).

\section{Idade}

No que diz respeito à idade, muitas são as investigações que sinalizam uma diminuição da frequência de comportamentos agressivos, nomeadamente diretos, com o avançar da idade (Tochigi et al., 2012; Williams \& Guerra, 2011). No mesmo sentido, Espelage e Horne (2008), afirmam que a frequência de bullying aumenta até ao final do ensino básico e diminui de frequência durante o ensino secundário. Saliente-se, contudo, a existência de trabalhos em que a variável idade não se mostrou um preditor do comportamento agressivo direto ou relacional (Larochete, Murphy, \& Craig, 2010; Lee, 2010; Stefanek, Strohmeier, Van de Schoot, \& Spiel, 2011; Tippett, Wolke, \& Platt, 2013). 


\section{Influências do micro-sistema}

A análise do micro-sistema sugere que a avaliação dos fatores de risco para o comportamento de violência escolar deva ter em conta, entre outras, as relações entre os jovens e os pais, as relações com os pares e o ambiente escolar (Hong \& Espelage, 2012).

\section{Relações jovens-família: Suporte social familiar}

As práticas parentais e o tipo de relacionamento com os filhos desempenham um papel importante no desenvolvimento de comportamentos agressivos (Smack, Kushner, \& Tackett, 2015) e de bullying (Holt \& Espelage, 2007). O suporte sociofamiliar surge assim como um fator de relevo para amenizar os problemas que afetam os adolescentes, nomeadamente as consequências dos comportamentos agressivos, em especial o bullying (Brank, Hoetger, \& Hazen, 2012). Seja como vítima ou agressor, os estudos sublinham a relação entre a perceção do suporte familiar e o envolvimento em comportamentos agressivos. Um ambiente familiar que apresente um bom suporte entre os seus membros, coesão, confiança e intimidade, mas também que permita uma comunicação dinâmica e empática, estimula o desenvolvimento psicossocial dos adolescentes (Duncan, 2004; Musito \& García, 2004; Matjasko, Needham, Grunden, \& Feldman, 2010). 0 bom suporte contribui, ainda, para a aquisição de competências sociais, bem como para o desenvolvimento da empatia, que surge como um fator protetor importante no âmbito dos comportamentos agressivos e anti-sociais (Li et al., 2015; López, Pérez, Ochoa, \& Ruiz, 2008). Por outro lado, uma perceção negativa deste suporte, caracterizado por um fraco envolvimento familiar, conflitos e problemas comunicacionais, parece isolar os adolescentes das influências positivas da família, tornando-os mais vulneráveis à violência (Matjasko et al., 2010).

Os estudos sugerem que as crianças agressivas reativamente são mais impulsivas e emocionais, experienciam mais situações de conflitos familiares, e apresentam problemas de temperamento (Vitaro \& Brendgen, 2005). Paralelamente, as crianças que agridem instrumentalmente tendem a experienciar boas interações familiares, mas com menor supervisão parental, quando comparadas com as crianças agressivas reativamente (Vitaro \& Brendgen, 2005).

\section{Relações jovens-pares: Suporte social dos amigos, influência dos pares e estatuto social}

Os grupos de pares desempenham um papel de destaque na modelagem dos comportamentos agressivos dos adolescentes, constituindo um meio facilitador da aprendizagem e desenvolvimento, com efeitos potencialmente significativos no controlo da agressividade (Pokhrel, Sussman, Black, \& Sun, 2010).

As amizades percecionadas como fonte de suporte social parecem estar relacionadas com um maior bem-estar psicossocial e registos mais baixos de agressividade para com os colegas (Marsh, McGee, \& Williams, 2014). Assim, não é de surpreender que relações negativas entre pares e a ausência de suporte dos mesmos representem importantes fatores de risco também no comportamento de bullying (Hong \& Espelage, 2012). Contudo, também as crenças sobre a agressão e o bullying, bem como aceitar ou não este tipo de comportamento, poderão ser fortes preditores (Palacios \& Berger, 2016).

Quando os contextos onde estão inseridos aprovam os comportamentos agressivos ou de bullying, os adolescestes tornam-se mais propensos a adquirir o mesmo padrão comportamental (Sijtsema et al., 2010). A relação com os colegas que tolerem comportamentos agressivos e que apresentem elevados níveis de conflituosidade, encontra-se associada a uma maior incidência de jovens agressores (Swearer \& Hymel, 2015). Por exemplo, no âmbito do bullying, os jovens com um padrão de rejeição social, normalmente identificados como alunos de risco, apresentam comportamentos agressivos mais impulsivos e diretos reativos, baixas competências sociais e pobre rendimento académico, sendo apenas aceites pelos pares com quem interagem (pequeno grupo igualmente marginalizado), e que os influenciam negativamente (Cook et al., 2010). Com uma rede de suporte mais alargada, o mesmo padrão comportamental pode ser observado no que concerne à agressão instrumental. Os resultados do estudo de Sijtsema et al. (2010), demonstraram que os jovens agressivos instrumentalmente se relacionam com outros com os mesmos níveis de agressão instrumental, nomeadamente os rapazes. Ainda que a atribuição de um valor social positivo possa potenciar esses comportamentos, o oposto parece diminuir a sua emergência. Ou seja, as crenças normativas que valorizam o comportamento pró-social poderão enfraquecer o valor social atribuído aos comportamentos agressivos e de bullying e, desta forma, fazer diminuir a sua incidência (Palacios \& Berger, 2016).

Porém, os contextos onde os jovens se inserem poderão ainda desencadear a atribuição de funções sociais a determinados comportamentos, como forma de atingir objetivos e a aprovação social (Ojanen, Grönroos, \& Salmivalli, 2005). São exemplo, os estudos que têm vindo a demonstrar que a agressão, nomeadamente a relacional, se associa com popularidade (e.g., Rose, Swenson, \& Waller, 2004), visibilidade e ser identificado como "fixe" pelos pares (Rodkin, Farmer, Pearl, \& Acker, 2006). 
Salmivalli (2010), concluiu que a relação entre os colegas dentro da mesma turma pode ser ambivalente. Os elementos de uma turma poderão unir-se contra o comportamento de bullying, promovendo a rejeição do bully ou poderão agrupar-se a favor do mesmo, aprovando e reforçando o seu comportamento. A difusão de responsabilidade no grupo-turma, o reforço mútuo, a tentativa de ganhar estatuto social juntando-se ao bully e evitando a vítima, imitar o bully que é percecionado como "fixe", ser aceite pelo mesmo, ou procurar integrar o grupo adaptando-se ao comportamento agressivo, são alguns dos motivos explicativos do processo de influência social (Samivalli, 2010) no comportamento agressivo e de bullying.

Estes factos levam-nos a questionar o que está na base do processo de decisão dos jovens que testemunham comportamentos agressivos ou de bullying, ou seja, o que os leva a estarem contra, não se manifestarem ou unirem-se aos perpetradores. Procurando responder a esta questão, Ferráns, Selman e Feigenberg (2012), concluíram que os jovens respondem ao comportamento de bullying, adotando estratégias que lhes permitam proteção e satisfação das suas necessidades pessoais, mediante as regras culturais inerentes aos diferentes grupos onde se inserem. Identificaram como necessidades pessoais as motivações para a ação, tais como a necessidade de proteção, segurança, de se unirem aos outros e de poder. Por sua vez, as regras culturais referiam-se às indicações, implícitas ou explícitas, dos amigos, pares e professores, sobre a forma como os membros do grupo deveriam responder perante diferentes situações dentro do contexto escolar.

\section{Relações jovens-escola: Ambiente escolar}

Grande parte dos investigadores acreditam que o ambiente escolar tem um enorme impacto nas atitudes e comportamentos dos jovens, nomeadamente na prevalência do comportamento agressivo e de bullying (e.g., Kasen, Jonhson, Chen, Crawford, \& Cohen, 2011; Orpinas, Horne, \& Staniszewski, 2003; Swearer, Espelage, \& Napolitano, 2009). Esta dimensão diz respeito à qualidade e à atmosfera da vida escolar, incluindo aspetos como os valores da escola, os relacionamentos interpessoais, a aprendizagem e o ensino, a liderança e as estruturas organizacionais (Cohen, 2009).

A perceção de um contexto escolar negativo, violento, com fraco suporte por parte dos professores, ou inadequadas respostas dos mesmos e da escola perante a violência, pode contribuir para o desenvolvimento e manutenção de comportamentos agressivos, nomeadamente de bullying (Giovazolias, Kourkoutas, Mitsopoulou, \& Georgiadi, 2010; Swearer \& Hymel, 2015). Por outro lado, os alunos que percecionam um ambiente escolar positivo, bem como aqueles que se sentem incluídos na sua escola, envolvem-se menos frequentemente em comportamentos agressivos (Marsh et al., 2014).

Assim, as perceções dos alunos do seu ambiente escolar poderão influenciar as suas experiências, bem como as suas escolhas, quando enfrentam comportamentos como o bullying (Ferráns \& Selman, 2014). Alunos que avaliem o ambiente escolar como "ambiente de sobrevivência", onde os conflitos se resolvem de forma impulsiva e com estratégias irrefletidas, apresentam uma maior propensão para se envolverem em comportamentos de risco e uma maior tendência para práticas de violência na escola. Um contexto escolar onde a resolução de conflitos se baseie fundamentalmente no exercício do poder e onde a sua resolução assente em normas unidirecionais e de conformidade, tem maiores probabilidades de evidenciar comportamentos agressivos. Por outro lado, os ambientes escolares onde a resolução de conflitos tem por base o "respeito" e o "cuidado", e onde estes se resolvem pelo recurso a métodos comunicacionais, ao compromisso e à colaboração, apresentam baixos níveis de violência escolar e os jovens envolvem-se menos em comportamentos de risco (LaRusso \& Selman, 2011).

Ferráns e Selman (2014), concluíram que num clima escolar autoritário, existe uma fraca coesão entre os alunos e entre estes e os professores. As suas regras geram um clima de desconfiança e de fraca envolvência, levando a que os jovens que presenciam comportamentos de bullying não se manifestem. Paralelamente, num ambiente escolar coeso, as regras são interpretadas como protetoras e reforçam o sentido de pertença, levando a que os jovens adotem uma posição contra o comportamento de bullying.

Apesar de na sua larga maioria, os estudos enfatizarem o ambiente escolar como fator importante no funcionamento psicossocial dos jovens (Espelage \& Swearer, 2003), o trabalho de Pellegrini e Bartini (2000) evidenciou um impacto mínimo deste aspeto no desenvolvimento de comportamentos de bullying.

\section{BULLYING E AGRESSÃO: PREVENÇÃO E INTERVENÇÃO}

Na fase da adolescência, são numerosos os fatores de risco e protetores da agressão e vitimização relacionados com o contexto escolar. É na escola que os jovens passam grande parte do seu tempo, sendo esta considerada um dos ambientes com maior influência e importância para o desenvolvimento dos jovens. Assim, cabe a esta implementar programas e políticas que fomentem um clima de segurança e que promovam o seu desenvolvimento saudável, assumindo um papel fundamental na deteção e intervenção 
perante os fatores de risco e protetores associados aos comportamentos agressivos e de vitimização (Feigenberg, Watts, \& Buckner, 2010).

Muitos programas de intervenção no comportamento de bullying falham ao não conseguirem operacionalizar a relação de poder assimétrica e a avaliação precisa da repetição temporal (Rodkin et al., 2015). De acordo com Vaillancourt et al. (2008), os motivos podem relacionar-se com as cognições dos jovens. A questão que permite a reflexão pessoal "já sofreu de bullying", por norma, leva os jovens a pensar em agressões ou ataques com significado pessoal ou que os amedrontam. Estes raramente ponderam ou se referem à repetição desse comportamento ou, se o poder entre as partes é desigual ou não. Deverão ainda dar resposta às questões sobre o tipo de relação existente entre os perpetradores de comportamento agressivo e as suas vítimas, igualmente relevante para a caracterização do comportamento de bullying e onde reside a distinção nuclear perante a generalidade do comportamento agressivo (Rodkin et al., 2015).

A dificuldade na operacionalização do bullying, tem conduzido a que os programas para a sua prevenção, nomeadamente os que se sustentam na perceção de suporte social, abordem este problema apenas do ponto de vista comportamental. Por norma evitam o uso do termo bully, redefinindo a conceptualização de bullying de modo a focarem-se predominantemente nos comportamentos agressivos que lhe estão subjacentes (e.g., bater, ameaçar, chamar nomes). Paralelamente, relativizam as condições subjetivas da avaliação do diferencial de poder e desvalorizam a dinâmica interpessoal existente entre as crianças que praticam bullying e os pares que estas intimidam (Ross \& Horner, 2009).

Salienta-se ainda, que os estudos que recorrem a medidas de auto-relato para identificação das categorias de comportamentos agressivos, nomeadamente as funções reativa e proativa da agressão, têm falhado na sua avaliação. Embora, teoricamente, apresentem relações diferenciadas com o ajustamento social, a avaliação psicométrica da agressão reativa e proativa tem evidenciado uma elevada correlação (Card \& Little, 2006), levantando questões sobre a validade na distinção destes dois constructos. Neste sentido, Little, Jones, Henrich e Hawley (2003) desenvolveram um trabalho onde apresentaram e validaram um instrumento para o estudo das formas e funções da agressão, cujos resultados suportaram uma clara distinção entre a agressão reativa e proativa. Estes autores sublinharam que os estudos que pretendiam avaliar as funções da agressão falhavam ao não considerarem as formas da agressão (direta e relacional). 0 instrumento que desenvolveram, permite distinguir claramente as formas puras de comportamento agressivo (e.g., "Eu bato e dou pontapés nos outros."), mas também as suas funções (e.g., função instrumental "Para obter o que eu quero, eu bato e dou pontapés nos outros.") (Sijtsema et al., 2010).

Talvez estes sejam parte dos motivos pelos quais os resultados dos programas anti-bullying têm apresentado efeitos moderados (Ttofi \& Farrington, 2011). Revela-se, pois, importante compreender os elementos que compõem estes programas e que contributos apresentam na redução destes comportamentos. No estudo de Ttofi e Farrington (2011), a diminuição do número de situações de vitimização encontrava-se associada com programas que incluíam métodos disciplinares não punitivos, sessões de formação com pais, recurso a vídeos e trabalho de grupo cooperativo. Também a duração do programa se encontrava associada à diminuição da frequência de vitimização. Todavia, a diminuição dos comportamentos de bullying, requeria mais elementos nesses programas. Para além dos acima expostos, a supervisão nos pátios, a gestão em sala de aula, a formação de professores, o estabelecimento de regras na sala de aula, o estabelecimento de um programa anti-bullying na escola, as sessões de esclarecimento na escola e a informação para pais também figuravam nos planos desses programas.

Apesar dos programas direcionados para o bullying apresentarem resultados inconsistentes, parece haver um consenso para aqueles que recorrem às intervenções socioemocionais e que tratam dos conflitos interpessoais e fazem gestão emocional. Estes têm apresentado resultados de sucesso na diminuição da violência nos jovens, incluindo o bullying (Brown, Low, Smith, \& Haggerty, 2011), mas também na diminuição de comportamentos disruptivos em sala de aula (Wilson \& Lipsey, 2007). Uns abrangem toda a escola, e outros apenas crianças sinalizadas com problemas de comportamento. Ambos colocam ênfase nos fatores sociais e emocionais relacionados com o desenvolvimento de condutas agressivas ou com o uso de instrumentos no seu controlo (e.g., competências sociais ou gestão emocional). Em complemento a uma abordagem mais ampla e designados por programas multimodais, estão o aconselhamento e a mediação de conflitos (Wilson \& Lipsey, 2007), que permitem incluir na intervenção os pais, professores e administradores, em adição ao programa designado para os alunos.

Resumidamente, na prevenção do bullying e da agressão salienta-se a importância de programas focados nos antecedentes dos comportamentos agressivos dos jovens e na promoção do seu bem-estar biopsicossocial. Enfatiza-se ainda, o foco destes programas estar na promoção de um ambiente escolar mais seguro e de comportamentos sociais positivos. Mas também, o benefício de envolver os membros da comunidade educativa e os pais nas estratégias interventivas. Programas que agreguem todos estes 
fatores parecem apresentar uma maior eficácia na minimização do risco da ocorrência destes comportamentos na escola.

\section{OBJETIVO DO ESTUDO}

Com o intuito de desenhar e implementar um programa preventivo e interventivo da agressão e violência escolar, este estudo apresenta dois objetivos principais. Por um lado, visa estudar os fatores de risco associados à agressão reativa e proativa no contexto escolar, recorrendo ao modelo ecológico. Neste sentido, foram formuladas as seguintes hipóteses:

a) A agressão reativa terá como preditores o fraco suporte nas relações parentais e nas relações de amizade, fraca satisfação com suporte social disponível e uma avaliação negativa do ambiente escolar.

b) A agressão proativa (instrumental) terá como preditores uma relação positiva com a família, uma maior rede de suporte social e baixos níveis de coesão quanto ao ambiente escolar.

Por outro lado, entender de que forma o estudo dos fatores de risco contribui para as estratégias a delinear no âmbito do programa de intervenção.

\section{MÉTODO}

\section{Participantes}

Participaram no estudo 851 adolescentes portugueses (402 do género feminino e 449 do género masculino), com idades compreendidas entre os 11 e os 19 anos $(M=15, D P=1,9)$, adotando os limites cronológicos da adolescência definidos pela Organização Mundial da Saúde (OMS), que limita esta faixa etária entre os 10 e os 19 anos (adolescents) (Eisenstein, 2005). Os jovens, maioritariamente de etnia causasiana (91\%), frequentavam uma escola do ensino público do concelho de Almada $(45,1 \%$ a frequentar o 3. ciclo do ensino básico e 54,9\% o ensino secundário). Cerca de um terço (30,5\%) já tinha repetido pelo menos um ano curricular e 8,6\% repetia o corrente ano. No que concerne aos progenitores, as mães tinham uma média de idades de 45 anos $(M=44,69 ; D P=5,39)$ e os pais de 47 anos $(M=46,9$; $D P=6,27)$. A maioria dos pais apresentou um nível de escolaridade diferenciado ao nível do ensino superior, encontravam-se casados/união de facto (63\%), com estatuto socioeconómico médio $(57,1 \%)$.

\section{Instrumentos \\ Escala de Auto-Avaliação da Agressão}

No original Little Aggression Inventory (LAI; Little et al., 2003), composta por 36 itens de autorresposta, esta escala permite distinguir as formas (direta e relacional) e as funções (reativa e instrumental) da agressão. Apresenta seis subescalas sendo cada uma formada por seis itens: forma pura de agressão direta (e.g., "Sou o tipo de pessoa que bate, dá pontapés ou socos a outras pessoas."); agressão direta reativa (e.g., "Quando sou ameaçado por alguém, muitas vezes ameaço de volta."); agressão direta instrumental (e.g., "Começo brigas frequentemente para conseguir o que quero."); forma pura de agressão relacional (e.g., "Sou o tipo de pessoa que diz aos amigos para pararem de gostar de alguém."); agressão relacional reativa (e.g., "Se outras pessoas me chateiam ou magoam, eu digo frequentemente aos meus amigos para deixarem de gostar delas."); e agressão relacional instrumental (e.g., "Eu digo frequentemente aos meus amigos para deixarem de gostar de alguém, para conseguir o que eu quero"). As respostas podem variar entre 1 (não é verdade) e 4 (completamente verdade), com valores de consistência interna situados entre os .62 e os .84 na sua estrutura original. Outras investigações apontaram valores adequados de fiabilidade e adequação do modelo para cada subescala (Fite, Stauffacher, Ostrov, \& Colder, 2008; Little, Brauner, Jones, Nock, \& Hawley, 2003; Little et al., 2003). Este estudo encontrou valores de consistência interna adequados para todas as subescalas, com alfas entre os .71 e os .95.

\section{Escalas de Perceção de Suporte Social da Família (PSS-Fam) e dos Amigos (PSS-Am)}

Medidas da Perceção do Suporte Social-Família (PSS-Fam) e Perceção do Suporte Social-Amigos (PSS-Am) (Gouveia, Leal, \& Cardoso, 2015), adaptadas e aferidas a partir do Perceived Social Support From Friends (PSS-Fr) and From Family (PSS-Fa) (Procidano \& Heller, 1983).

Constituídas por 20 itens cada, numa escala nominal de 3 pontos ( $\operatorname{sim}$, não e não sei), as Escalas de Perceção de Suporte Social da Família (e.g., "A minha família dá-me o apoio moral que preciso.") e de Perceção de Suporte Social dos Amigos (e.g., "Os meus amigos gostam de ouvir a minha opinião."), avaliam sentimentos e experiências dos adolescentes face a situações que possam ocorrer no âmbito das suas relações com a sua família de origem e com os seus amigos. A pontuação é obtida somando um ponto por cada item que reflita apoio social percebido. As escalas apresentam bons índices de fiabilidade na 
amostra em estudo, com alfa de Cronbach de .87 para a perceção do suporte social dos amigos e de .84 da família.

\section{Questionário de Suporte Social - Versão Reduzida (QSS6)}

Do original Social Support Questionnaire - Short Form (Sarason, Levine, Basham, \& Sarason, 1983), o questionário é constituído por 6 itens, cada um deles com duas partes, originando dois resultados parciais. As respostas à primeira parte poderão variar entre 0 e 9 . Por exemplo, à questão "Quando precisas de ajuda em quem podes confiar?" o sujeito poderá responder no mínimo 0 (ninguém), ou mencionar até um número máximo de 9 pessoas percebidas como estando disponíveis para o apoiarem e ajudarem numa determinada situação. Na segunda parte, pede-se ao sujeito que avalie de uma forma global o suporte percebido nessa mesma situação, recorrendo a uma escala do tipo Likert de 6 pontos (de muito insatisfeito (1) a muito satisfeito (6)). 0 conjunto dos 6 itens permite obter dois índices: o índice de perceção de suporte disponível (QSS6N; índice numérico) e o índice de perceção da satisfação com o suporte social disponível (QSS6S; índice de satisfação). Outras investigações apontam valores adequados de fiabilidade para as duas escalas (Pinheiro \& Ferreira, 2002; Sarason et al., 1983). Os alfas de Cronbach para a amostra em estudo foram de .92 para o QSS6N e de .95 para o QSS6S.

\section{Questionário de Ambiente Escolar (QAE)}

Do original School Climate Questionnaire (Scherman, 2005), é constituído por 51 itens, avaliados duplamente (situação real/situação desejada), permitindo avaliar o ambiente escolar através da recolha das opiniões e atitudes dos alunos no que se refere à escola, aos professores, colegas e aos próprios. As 5 dimensões que possibilitam avaliar o ambiente escolar são: violência (uso da força com a intenção de magoar outra pessoa, bem como formas mais subtis de violência, tais como a utilização de linguagem ofensiva e humilhação; e.g., "Na escola costuma haver lutas entre colegas."); ambiente de ensino (estrutura, recursos e ambiente físico no qual o aluno se insere, seja dentro da sala de aula ou no setting escolar; e.g., "O ambiente académico nesta escola contribui para a nossa aprendizagem."); interação (a estima que se desenvolve entre duas partes em interação uma com a outra, por exemplo considerar alguém como sendo de valor, saber que irá ser honesta, justa e confiável; e.g., "Os professores respeitam (de forma igual) todos os alunos da escola."); coesão (refere-se aos alunos enquanto grupo/unidade e inclui aspetos da dinâmica interpessoal que estes têm com as figuras de autoridade da escola; e.g., "Quando é preciso os alunos ajudam-se uns aos outros na sala de aula."), e recursos (os equipamentos e estruturas que a escola tem à sua disposição; sobre este fator pesam também a clareza das regras da escola e a capacidade do seu diretor cumprir as suas promessas, pois recai sobre este elemento a manutenção dos recursos da escola; e.g., "As regras da escola são claras/estão bem estabelecidas."). Os valores de consistência interna na escala original variam entre .65 e .79. A análise de fiabilidade na amostra em estudo revelou valores de alfa ligeiramente melhores que na sua versão original, variando entre .77 e .85 .

\section{Procedimento}

A recolha de dados foi realizada em setembro de 2012, no contexto de sala de aula, seguindo-se 2 anos letivos de implementação de um projeto interventivo e preventivo da agressão e violência escolar.

Pais e encarregados de educação receberam uma carta com informações sobre o estudo e com o pedido de autorização para o(s) seu(s) educando(s) preencherem os questionários. Após uma semana do envio da carta aos pais, todos os alunos que receberam autorização do(a) encarregado(a) de educação, procederam ao preenchimento dos instrumentos. A fim de responder a perguntas que pudessem surgir, estiveram presentes elementos da equipa de investigação durante toda a sua aplicação. Os alunos foram instruídos para não escreverem os seus nomes nos questionários, tendo-lhes sido atribuído um número de código, preservando a confidencialidade do material recolhido. No final os questionários foram selados pelos alunos num envelope e entregues ao investigador.

Após análise dos preditores do comportamento agressivo na amostra em estudo, foram delineadas as estratégias a incluir no programa de intervenção. A intervenção visava a criação de um Gabinete do Aluno e da Família (GAF). O GAF pretendia uma abordagem multidimensional do comportamento agressivo no espaço ecológico-social dos jovens (consultar modelo de atuação em Almeida \& Gouveia, 2016), complementar às medidas já adotadas pela escola no combate à violência escolar (e.g., sancionatórias, videovigilância, protocolo com o programa nacional Escola Segura). 


\section{Análise dos dados}

A análise estatística incluiu medidas de estatística descritiva e análise inferencial. 0 nível de significância foi fixado em $\alpha \leq .05$. As comparações entre dimensões realizaram-se através do teste $t$-student para amostras emparelhadas (dimensões do suporte social) e Anova Repeated Measures (dimensões do ambiente escolar e das formas e funções da agressão). As variáveis nominais foram transformadas em variáveis dummy, como foi o caso do género e da repetição escolar.

Para analisar se valores elevados registados nalgumas variáveis (e.g., suporte social dos amigos PSS-Am) representavam fatores de risco para o desenvolvimento de outro tipo de problemas (e.g., agressão direta reativa), foram criados vários modelos recorrendo a regressões lineares hierárquicas, onde a idade, o género e a repetição escolar entraram no Passo 1, as variáveis preditoras do suporte social entraram no Passo 2 e, as variáveis preditoras do ambiente escolar, no Passo 3. Os pressupostos da regressão linear múltipla, designadamente a linearidade da relação entre as variáveis independentes e a variável dependente (análise gráfica), independência de resíduos (teste de Durbin-Watson), normalidade dos resíduos (teste de Kolmogorov-Smirnov), multicolinearidade (VIF e Tolerance) e homogeneidade de variâncias (análise gráfica) foram analisados e encontravam-se genericamente satisfeitos. A análise estatística foi efetuada com o SPSS (Statistical Package for the Social Sciences) versão 22.0 para Windows e com software Amos (v. 22.0 para Windows).

\section{RESULTADOS}

Na Tabela 1 podemos observar o número de respostas válidas, os valores mínimos e máximos, as médias, desvios padrão, comparações entre dimensões do suporte social, ambiente escolar e formas e funções da agressão, e respetivo tamanho do efeito.

Tabela 1. Análise descritiva: respostas válidas, mínimo e máximo, médias, desvios padrão, comparações e tamanho do efeito para as dimensões de avaliação do suporte social, ambiente escolar e formas e funções da agressão.

\begin{tabular}{|c|c|c|c|c|c|c|c|}
\hline & $\mathbf{N}$ & Mín. & Máx. & $M$ & $D P$ & $p$ & $\eta^{2}$ \\
\hline \multicolumn{8}{|l|}{ Suporte social } \\
\hline PSS-Am (amigos) & 851 & 0.00 & 20 & 13.02 & 5.13 & .854 & .001 \\
\hline PSS-Fam (familiar) & & 0.00 & 20 & 13.05 & 4.86 & & \\
\hline QSS6 numérico & 806 & 0.00 & 9.00 & 3.61 & 1.89 & $.001^{* * *}$ & .001 \\
\hline QSS6 satisfação & & 1.00 & 6.00 & 4.95 & 1.07 & & \\
\hline Ambiente escolar (situação real) & 840 & & & & & $.001^{* * *}$ & .326 \\
\hline Violência & & 1.23 & 4.00 & 2.33 & 0.43 & & \\
\hline Ambiente de ensino & & 1.27 & 4.00 & 2.93 & 0.42 & & \\
\hline Interação & & 1.00 & 4.00 & 2.83 & 0.51 & & \\
\hline Coesão & & 1.00 & 4.00 & 2.75 & 0.37 & & \\
\hline Recursos & & 1.00 & 4.00 & 2.95 & 0.49 & & \\
\hline \multicolumn{8}{|l|}{ Agressão } \\
\hline Agressão Direta & 846 & & & & & $.001^{* * *}$ & .256 \\
\hline Forma Pura de Agressão Direta & & 1.00 & 4.00 & 1.18 & 0.40 & & \\
\hline Agressão Direta Reativa & & 1.00 & 4.00 & 1.42 & 0.55 & & \\
\hline Agressão Direta Instrumental & & 1.00 & 4.00 & 1.10 & 0.39 & & \\
\hline Agressão relacional & 846 & & & & & $.001^{* * *}$ & .100 \\
\hline Forma Pura de Agressão Relacional & & 1.00 & 4.00 & 1.19 & 0.41 & & \\
\hline Agressão Relacional Reativa & & 1.00 & 4.00 & 1.24 & 0.45 & & \\
\hline Agressão Relacional Instrumental & & 1.00 & 4.00 & 1.11 & 0.38 & & \\
\hline
\end{tabular}

No que concerne à perceção que os jovens têm de se envolverem em comportamentos agressivos, constatamos que o índice de agressão foi baixo. A maioria dos jovens desta amostra utilizava um tipo de agressão direta reativa $(M=1.42)$, enquanto que a agressividade direta instrumental foi a forma de agressão menos utilizada $(M=1.11)$. A agressão relacional do tipo reativo apresentou-se a segunda forma de agressão mais utilizada por estes adolescentes $(M=1.24)$.

Os jovens desta amostra referiram estar satisfeitos com o suporte social familiar $(M=13.05)$ e com o suporte social dos amigos $(M=13.02)$. Referiram ainda um baixo suporte social disponível $(M=3.61)$, mas revelando um elevado grau de satisfação com o número de pessoas percebidas como estando disponíveis para os apoiarem e ajudarem numa determinada situação $(M=4.95)$.

No que se refere ao ambiente escolar (perceções de situações reais) os jovens percecionaram baixos índices de violência $(M=2.33)$ e avaliaram positivamente o ambiente de ensino, a interação, a coesão e os recursos disponíveis na escola $(M \cong 3)$. 
Relativamente às diferenças entre o QSS numérico e QSS satisfação estas foram estatisticamente significativas $t(805)=-19.564, p=.001, \eta^{2} p=.001, \pi=1.000$. Também as diferenças entre as dimensões da agressão direta $F(2,1690)=406,704, p=.001, \eta^{2} p=.256, \pi=1.000$ e da agressão relacional $F(2$, $1690)=93.939, p=.001, \eta^{2} p=.100, \pi=1.000$, se apresentaram estatisticamente significativas. Com exceção para a diferença entre as dimensões do ambiente de ensino e dos recursos, todas as diferenças foram estatisticamente significativas, entre as dimensões do ambiente escolar $F(4,3356)=406,704, p=$ $.001, \eta^{2} p=.326, \pi=1.000$.

Nas Tabelas 2 e 3 encontramos os resultados das regressões lineares hierárquicas tendo como variáveis independentes os fatores individuais no Passo 1; a perceção do suporte social no Passo 2 e, perceção do ambiente escolar no Passo 3. Como varáveis dependentes temos a forma e funções de agressão direta na Tabela 2 e a forma e funções de agressão relacional na Tabela 3.

\section{Preditores das funções reativa e instrumental da agressão direta}

A variância total explicada para a agressão direta (consultar Tabela 2) variou entre um máximo de 12.6\% (agressão direta reativa como variável dependente) e um mínimo de 10.3\% (agressão direta instrumental como variável dependente). Assim, o modelo que melhor explicou a agressão direta foi o da agressão direta reativa (12.6\% da variância total) pelos fatores individuais (5.8\% da variância do modelo), seguido do modelo de agressão direta - forma pura (11.7\% da variância total).

Tabela 2. Análises de regressão linear hierárquica: preditores das funções da agressão direta.

\begin{tabular}{|c|c|c|c|c|c|c|}
\hline \multirow[b]{3}{*}{ Preditor } & \multicolumn{6}{|c|}{ Agressão Direta } \\
\hline & \multicolumn{2}{|c|}{ Forma Pura } & \multicolumn{2}{|c|}{ Reativa } & \multicolumn{2}{|c|}{ Instrumental } \\
\hline & $\Delta R^{2}$ & B & $\Delta R^{2}$ & B & $\Delta R^{2}$ & B \\
\hline Passo 1 & .022 & & .058 & & .019 & \\
\hline Idade & & .012 & & .008 & & -.002 \\
\hline Género (feminino) & & $-.061^{*}$ & & $-.189^{* * *}$ & & $-.063^{*}$ \\
\hline Repetição escolar (sim) & & .008 & & .086 & & .024 \\
\hline Passo 2 & .050 & & .038 & & .045 & \\
\hline PSS-Am (amigos) & & -.001 & & -.002 & & -.004 \\
\hline PSS-Fam (familiar) & & $-.009^{* *}$ & & $-.013^{* *}$ & & -.003 \\
\hline QSS6 numérico & & -.008 & & -.010 & & -.014 \\
\hline QSS6 satisfação & & $-.036^{* *}$ & & -.031 & & $-.040^{* *}$ \\
\hline Passo 3 & .045 & & .031 & & .039 & \\
\hline AE Violência & & $.139^{* * *}$ & & $.151^{* * *}$ & & $.120^{* * *}$ \\
\hline AE Ensino & & $-.162^{* *}$ & & $-.155^{*}$ & & $-.193^{* * *}$ \\
\hline AE Interação & & $-.087^{*}$ & & $-.158^{* *}$ & & -.064 \\
\hline AE Coesão & & .049 & & .127 & & $.133^{*}$ \\
\hline AE Recursos & & $.129^{* *}$ & & $.148^{*}$ & & .082 \\
\hline Total $\mathbf{R}^{2}$ & .117 & & .126 & & .103 & \\
\hline$F(12,784)$ & $8.622^{* * *}$ & & $9.418^{* * *}$ & & $7.511^{* * *}$ & \\
\hline
\end{tabular}

Nota. ${ }^{*} p<.05 ;{ }^{* *} p<.01 ;{ }^{* * *} p<.001$

No que concerne aos fatores individuais, a variável género (feminino) foi preditor significativo das funções da agressão direta. Apresentou uma associação negativa com a agressão direta reativa $\beta=-.189, p$ $=.000$ e com a agressão direta instrumental $\beta=-.063, p=.023$.

Relativamente ao suporte social, a perceção de suporte social da família mostrou-se um preditor significativo, e evidenciou uma associação negativa com a agressão direta reativa $\beta=-.013, p=.003$. 0 grau de satisfação com o suporte social percebido $\beta=-.040, p=.003$, apresentou uma associação significativa e negativa com o desenvolvimento de agressão direta instrumental.

No que refere ao ambiente escolar, a dimensão da violência foi um indicador significativo e positivo das funções da agressão direta reativa $\beta=.151, p=.001$ e instrumental $\beta=.120, p=.000$. A função reativa $\beta=-.155, p=.040$ e instrumental $\beta=-.193, p=.000$ da agressão direta, evidenciaram associações significativas e negativas com a dimensão ambiente de ensino. Apenas a agressão direta reativa foi predita, negativamente, pela dimensão da interação $\beta=-.158, p=.005$, e positivamente pelos recursos $\beta$ $=.148, p=.022$. A agressão direta instrumental apresentou uma associação única e positiva, com a dimensão da coesão $\beta=.133, p=.014$.

\section{Preditores das funções reativa e instrumental da agressão relacional}

No que diz respeito à agressão relacional (Tabela 3), a variância total explicada variou entre um máximo de 11\% (agressão relacional instrumental como variável dependente) e um mínimo de 7.1\% (agressão 
relacional reativa como variável dependente). 0 modelo que melhor explicou a agressão relacional foi o da agressão relacional instrumental (11\% da variância total), pelos fatores suporte social (4.4\% da variância do modelo) e ambiente escolar ( $4.4 \%$ da variância do modelo), seguido do modelo de agressão relacional - forma pura (10.6\% da variância total).

Tabela 3. Análises de regressão linear hierárquica: preditores das funções da agressão relacional.

\begin{tabular}{|c|c|c|c|c|c|c|}
\hline \multirow[b]{3}{*}{ Preditor } & \multicolumn{6}{|c|}{ Agressão Relacional } \\
\hline & \multicolumn{2}{|c|}{ Forma Pura } & \multicolumn{2}{|c|}{ Reativa } & \multicolumn{2}{|c|}{ Instrumental } \\
\hline & $\Delta R^{2}$ & B & $\Delta R^{2}$ & B & $\Delta R^{2}$ & B \\
\hline Passo 1 & .017 & & .018 & & .022 & \\
\hline Idade & & .001 & & -.007 & & -.007 \\
\hline Género (feminino) & & $-.069^{*}$ & & $-.092^{* *}$ & & $-.077^{* * *}$ \\
\hline Repetição escolar (sim) & & .009 & & .017 & & .022 \\
\hline Passo 2 & .040 & & .030 & & .044 & \\
\hline PSS-Am (amigos) & & -.004 & & -.005 & & -.004 \\
\hline PSS-Fam (familiar) & & -.005 & & -.006 & & -.003 \\
\hline QSS6 numérico & & -.007 & & -.008 & & -.014 \\
\hline QSS6 satisfação & & $-.039^{* *}$ & & $-.032^{*}$ & & $-.036^{* *}$ \\
\hline Passo 3 & .048 & & .023 & & .044 & \\
\hline AE Violência & & $.180^{* * *}$ & & $.145^{* * *}$ & & $.135^{* * *}$ \\
\hline AE Ensino & & $-.153^{* *}$ & & -.112 & & $-.202^{* * *}$ \\
\hline AE Interação & & -.055 & & -.017 & & -.061 \\
\hline AE Coesão & & .089 & & .081 & & $.152^{* *}$ \\
\hline AE Recursos & & .084 & & .063 & & .091 \\
\hline Total $\mathbf{R}^{2}$ & .106 & & .071 & & .110 & \\
\hline$F(12,784)$ & $7.707^{* * *}$ & & $4.985^{* * *}$ & & $8.061^{* * *}$ & \\
\hline
\end{tabular}

Nota. ${ }^{*} p<.05 ;{ }^{* *} p<.01 ;{ }^{* * *} p<.001$

Os fatores individuais explicaram parcamente as funções da agressão relacional (1.8\% da variância do modelo da função reativa e $2.2 \%$ da variância do modelo da função instrumental). Ainda assim, a variável género (feminino) mostrou-se um indicador significativo e negativo quer da agressão relacional reativa $\beta=-.092, p=.005$ quer da agressão relacional instrumental $\beta=-.077, p=.005$.

No que concerne ao suporte social, apenas o grau de satisfação com a rede de suporte percecionada se associou, negativamente, com o desenvolvimento de agressão relacional reativa $\beta=-.032$, $p=.043$ e instrumental $\beta=-.036, p=.006$.

Relativamente ao ambiente escolar, a perceção de um ambiente escolar violento (valores elevados e positivos na dimensão violência) foi preditor das funções reativa $\beta=.145, p=.000$ e instrumental $\beta$ $=.135, p=.000$ da agressão relacional. A variável independente ambiente de ensino estimou negativa e significativamente a agressão relacional instrumental $\beta=-.202, p=.000$. A dimensão da coesão $\beta=.152, p$ $=.005$, apresentou uma associação significativa e positiva com o desenvolvimento de agressão relacional instrumental.

\section{DISCUSSÃO}

Os resultados obtidos apontaram para um índice de agressão baixo na amostra em estudo. Equacionamos, tal como LaRusso e Selman (2011), se estes são reflexo das medidas já adotadas pela escola no combate à violência escolar. Esta apresentava estratégias de resolução do conflito alicerçadas no poder administrativo, com normas sancionatórias bem estabelecidas, reconhecidas e aceites por todos os elementos da comunidade educativa. De acordo com estes autores, escolas com este modelo tendem a apresentar valores moderados de agressividade.

Apuramos ainda, um maior recurso a agressão reativa, seja de forma direta ou relacional. Assim, inferimos a importância de capacitar estes jovens para uma melhor regulação emocional e gestão dos conflitos.

De uma forma geral, os adolescentes desta amostra apresentaram-se satisfeitos com o seu suporte social e familiar. Ainda que tenham percecionado um baixo suporte social disponível, apresentaram um grau de satisfação elevado com o número de pessoas disponíveis para os apoiarem e ajudarem numa determinada situação. Estes resultados sustentam os estudos (e.g., Li et al., 2015) que afirmam que o bom suporte familiar poderá constituir um fator protetor de relevo no âmbito dos comportamentos agressivos e antissociais e que as amizades sentidas como fonte de suporte social parecem estar relacionadas com registos mais baixos de agressividade para com os colegas (Marsh et al., 2014). Todavia, questionamo-nos sobre o motivo pelo qual a rede de suporte é tão pequena e sobre o tipo de relações de amizade que estes 
jovens estabelecem. Neste sentido, depreendemos que o programa de intervenção deverá fomentar as relações sociais destes jovens com os pares, professores, pais, no sentido de aumentar essa mesma rede e fortalecer as relações entre estes.

No que respeita ao ambiente escolar, os jovens avaliaram positivamente o ambiente de ensino, a interação, a coesão e os recursos disponíveis na escola, resultados que refletem a perceção de um ambiente escolar positivo, o que, de acordo com Marsh et al. (2014) poderá ser indicativo de um envolvimento menos frequente em comportamentos agressivos. Apesar da perceção positiva dos alunos, uma primeira avaliação junto da direção da escola revelou um elevado número de problemas de conduta e de indisciplina, que conduziam a numerosas participações disciplinares. Embora não tenham sido detetados casos de bullying, mas sim pequenos conflitos entre pares, inferimos que o programa de intervenção poderá promover uma perceção ainda mais positiva do apoio social e do ambiente escolar. Mas também, prevenir o comportamento de bullying e reduzir o número de comportamentos agressivos, nomeadamente reativos, percecionados pelos alunos e que poderão estar na origem dos problemas de conduta sinalizados pela escola.

No que concerne à análise dos preditores, e no que respeita ao nível de influência individual preconizado no modelo ecológico, os resultados evidenciaram valores de agressividade direta e relacional, mas também reativa e instrumental, mais elevados nos rapazes. Estes resultados foram indicativos de que estes estão mais predispostos a envolverem-se em diferentes tipos de comportamentos agressivos, em conformidade com a maioria dos estudos na área da agressão e do bullying (Álvarez-García et al., 2015; Chang et al., 2013; Prodocimo et al., 2014).

No que respeita à variável idade, os nossos resultados seguiram também a tendência apontada em estudos anteriores (Larochete et al., 2010; Lee, 2010; Stefanek et al., 2011; Tippett et al., 2013), não se mostrando um preditor significativo da agressão direta e relacional, mas também das suas funções reativa e instrumental.

No que concerne à primeira hipótese, esta foi parcialmente corroborada. 0 suporte social dos amigos não se mostrou um preditor significativo das formas de agressão, nem das suas funções reativas, ainda que os estudos reforcem a sua importância (e.g., Marsh et al., 2014). Contudo, o fraco suporte sociofamiliar e o baixo grau de satisfação com o suporte disponível, foram preditores de agressão direta reativa, e de agressão relacional reativa, respetivamente, confirmando a hipótese inicial. Estes resultados reforçam, sobretudo, a importância da família e da construção de boas bases relacionais durante a infância. Quer isto dizer que, embora no período da adolescência os pares adquiram importância na regulação social dos jovens (Kendrick, Jutengren, \& Stattin, 2012; Seeds, Harkness, \& Quilty, 2010), o peso das relações familiares pré-estabelecidas no micro-sistema, que fundeiam e influenciam a vida futura dos adolescentes (Bronfenbrenner \& Morris, 1998), é considerável para o desenvolvimento ou não de comportamentos agressivos, nomeadamente reativos. Assim, pares que não estabeleçam e fortifiquem as relações sociais poderão sentir-se insatisfeitos e, desta forma, apresentar um baixo controlo nos impulsos, fazer interpretações erróneas dos problemas reagindo com hostilidade a provocações que percebam como ambíguas, apresentando um padrão de agressão reativo (Cook et al., 2010).

No que concerne ao ambiente escolar, os resultados não corroboraram na totalidade a nossa hipótese. A perceção de uma escola com violência foi preditor da agressão reativa, na sua forma direta e relacional. 0 pobre ambiente de ensino e a fraca interação entre alunos e entre estes e os professores, também foram identificados como fatores de risco para o desenvolvimento de agressão reativa, essencialmente na sua forma direta. Estes resultados reforçam os estudos que afirmam que um pobre ambiente escolar (violento, com fraco suporte por parte dos professores, ou inadequadas respostas dos mesmos e da escola perante este comportamento) pode contribuir para o desenvolvimento e manutenção de comportamentos agressivos, mas também de bullying (Giovazolias et al., 2010; Swearer \& Hymel, 2015). Deste modo, estratégias que fortifiquem estas relações serão de extrema importância no delineamento do programa interventivo.

Contudo, os resultados sustentaram que a avaliação de bons recursos (incluindo a clareza das regras da escola) intensificam a probabilidade de envolvimento em agressão reativa de forma direta. Esta associação está em linha com outras investigações (e.g., LaRusso \& Selman, 2011) que observaram que nas escolas com regras restritas, a probabilidade dos jovens se envolverem em comportamentos de risco é mais elevada. Contudo, questionamo-nos, pelo facto deste preditor se associar ao surgimento de agressão reativa, se estes jovens poderão vir a constituir-se bullies marginalizados, tal como referido por Rodkin et al. (2015). Discute-se ainda, se um regime mais autoritário poderá segregar e aproximar os alunos tidos como problemáticos ou com condutas consideradas desajustadas, que poderão apresentar níveis de hostilidade mais elevados condicionados pelo contexto.

Relativamente à segunda hipótese, o suporte social dos amigos e da família, mas também uma maior dimensão da rede social de apoio, não se mostraram preditores significativos para o 
desenvolvimento de agressão instrumental. Apenas a fraca satisfação com a rede de suporte social foi preditor do envolvimento neste tipo de agressão. Neste sentido, os resultados foram sugestivos de que a insatisfação com a rede de apoio é preditor de um maior envolvimento em agressão instrumental. Interrogamo-nos se a insatisfação com a rede de suporte é um meio facilitador do reforço deste comportamento, no sentido destes jovens poderem alcançar os seus objetivos (e.g., popularidade, serem idolatrados pelo grupo de pares) e obter ganhos instrumentais, tal como sugere Sijtsema et al. (2010).

No que concerne ao ambiente escolar, e contrariamente à hipótese formulada, a perceção de maiores níveis de coesão entre os colegas foi preditor de agressão instrumental. Tratando-se de uma escola com medidas bem definidas contra qualquer comportamento de abuso, seria esperado que elevados níveis de coesão se traduzissem em alunos com comportamentos pró-sociais, o que contribuiria para a não emergência deste tipo de agressão. Perante isto, questionamo-nos se o resultado obtido não poderá estar relacionado com o processo de influência social descrito por Salmivalli (2010). Ou seja, que a relação destes jovens dentro da turma se baseie na procura de popularidade dentro do grupo de pares, o que inevitavelmente poderá conduzir ao apoio deste tipo de comportamento, aumentando a sua ocorrência.

Assim, inferimos que alunos insatisfeitos com a rede de apoio (com comportamentos negativos), mas que encontrem um grupo de pares cujas normas de grupo permitam a sua inclusão no mesmo, estarão mais propensos a agressão instrumental, tal como sugere o modelo de dissimilaridade grupopessoa de Wright et al. (1986).

Resumidamente, salientamos a importância do bom suporte sociofamiliar e de uma escola onde a resolução de conflitos tenha por base o respeito e métodos comunicacionais, importantes na prevenção da agressão direta reativa, mas também de bullies marginalizados. Ressalvamos também a satisfação com o suporte social prestado, pela sua influência no desenvolvimento quer de agressão reativa (forma relacional), quer de agressão instrumental, seja na forma direta ou relacional. Chamamos ainda a atenção para a ambiguidade na avaliação dos níveis de coesão. Podemos pensar que uma turma coesa, numa escola com regras bem estabelecidas contra o comportamento agressivo, possa enfraquecer a sua emergência. Contudo, se a coesão dos alunos se dever a efeitos de popularidade e obtenção de estatuto dentro do grupo de pares, esta poderá potenciar o surgimento de comportamento agressivo instrumental (seja de forma direta ou relacional).

\section{Utilização dos preditores no desenho da intervenção}

0 segundo objetivo deste trabalho diz respeito à forma como o estudo dos fatores de risco poderá contribuir para as estratégias a delinear no âmbito do programa de intervenção.

Os baixos níveis de agressão encontrados na amostra em estudo, a ausência de comportamentos de bullying e a incidência de pequenos conflitos, problemas de conduta e de indisciplina, sugerem um modelo de intervenção universal. Estes são desenvolvidos no contexto de sala de aula para todos os alunos e não incluem uma seleção de sujeitos com necessidade específica de intervenção (Wilson \& Lipsey, 2007). Deste modo, consideramos que uma intervenção que reduza eficazmente os comportamentos agressivos, também irá reduzir o comportamento de bullying. As estratégias deverão ser orientadas para as intervenções socioemocionais, que contemplam a gestão emocional e os conflitos interpessoais. Estas têm apresentado resultados de sucesso na diminuição da violência nos jovens, incluindo o bullying (Brown et al., 2011), mas também na diminuição de comportamentos disruptivos em sala de aula (Wilson \& Lipsey, 2007).

0 programa deverá ainda fazer recurso a estratégias para resolução de conflitos. Uma estratégia que poderá favorecer a comunicação, o sentido de cooperação e o compromisso entre alunos, mas também entre estes e os professores, é a mediação de conflitos. A escola poderá adotar outras formas de solucionar os conflitos, nomeadamente a mediação entre pares, promovendo nos alunos a perceção de um sistema mais justo e reforçando o sentido de pertença à escola, tal como sugerem Ferráns e Selman (2014).

Os nossos resultados foram sugestivos de que a perceção que estes jovens têm dos seus contextos mais imediatos, tais como a escola, a família e os pares poderá potenciar o seu envolvimento em comportamentos agressivos, nomeadamente reativos. Tomando em consideração as sugestões de Little et al. (2003) para amostras que evidenciem níveis de agressão reativa, como é o caso, consideramos que o treino de competências pessoais e sociais poderá ser o mais adequado a todos os grupos-turma. Esta estratégia interventiva facilitará o ajuste comportamental, fomentará os comportamentos pró-sociais, reduzindo os problemas de conduta e os distúrbios emocionais por regra internalizados (Durlak, Weissberg, Dymnicki, Taylor, \& Schelliger, 2011). Ao fomentar os comportamentos pró-sociais poderá ainda contribuir para uma diminuição do risco de ocorrência de agressão proativa ou a incidência de bullies na turma. 
A presença e envolvência dos professores deverá ser considerada. Não só favorecerá a sua relação com os alunos (fator de risco assinalado para o desenvolvimento de comportamentos agressivos reativos e proativos na amostra em estudo), como também irá promover o aumento dos seus conhecimentos neste domínio. 0 risco encontrado entre a perceção de um fraco suporte familiar e o desenvolvimento de agressão reativa, é sugestivo de que também se deverão envolver os pais na escola. Desta forma, poderão ser implementadas sessões de aconselhamento para pais, mas também professores, e promover o envolvimento destes nas atividades do programa.

O fomentar de comportamentos pró-sociais nos alunos, o maior conhecimento dos professores e pessoal administrativo, mas também dos pais, o recurso a regras que promovam a inclusão social, facilitará a identificação e sinalização de alunos com comportamentos de risco, potencialmente marginalizados pelo recurso às regras restritas, mas também de alunos com problemas emocionais. Estes casos poderão ser intervencionados ao nível do aconselhamento individual e/ou encaminhados para os recursos na comunidade (e.g., apoio psicológico individual).

Em suma, o GAF deverá adotar uma abordagem pró-ativa de aconselhamento e de mediação, motivando os jovens e conferindo-lhes um papel de relevo e mais autónomo na prevenção do comportamento agressivo e de bullying. Mas também contribuir para um clima positivo na escola, capaz de enfrentar estes comportamentos. A abordagem ecossistémica poderá fomentar mudanças individuais, quer nos jovens, quer nos agentes educativos, mas também nas relações interpessoais que estes estabelecem no âmbito da sala de aula. Facilitará a comunicação dos alunos com os pais, mas também a relação dos últimos com a escola. Terá em consideração a articulação e colaboração com a direção escolar, para que se adotem políticas mais integradoras de prevenção deste comportamento, mas também com outras entidades na comunidade.

\section{Limitações}

Este estudo apresenta algumas limitações. Em primeiro lugar a sua natureza transversal, que não nos permitiu fazer uma análise prospetiva dos preditores das formas e funções da agressão. Em segundo, o uso exclusivo de instrumentos de autorrelato, o que torna a sua investigação insuficiente, pois os estudos (e.g., Blakely-McClure \& Ostrov, 2016; Ostrov, 2008, 2010) que utilizam métodos com multi-informantes têm-se revelado melhores na análise das relações e no fortalecimento das suas conclusões. Embora fosse nossa pretensão estudar as perceções dos adolescentes no que concerne à agressão pelos pares, poderia ter sido uma mais valia avaliar conjuntamente as perceções dos pais e/ou dos professores, nas análises dos fatores de risco e protetores.

\section{Conclusão}

Apesar das limitações apontadas, os resultados deste estudo contribuíram significativamente para a parca literatura que explora, conjuntamente, as formas e funções da agressão em diferentes grupos. Esta forma de análise permite aferir o que leva os jovens a comportarem-se agressivamente, mas também o que os motiva para a agressão. A distinção clara entre a agressão reativa e proativa, revelou-se particularmente importante na compreensão dos padrões de risco e de proteção ao desenvolvimento de comportamentos agressivos, incluindo o bullying.

Esta avaliação permitiu ainda, estruturar e delinear ações preventivas e interventivas específicas ao contexto escolar em análise. Devemos considerar que os fatores de risco são específicos a diferentes contextos, pelo que devem ser tidos em consideração quando se procura desenhar e implementar um programa interventivo. Assim sendo, as escolas que pretendam implementar programas socioemocionais, em complemento aos de carácter mais sancionatório, deverão ter em consideração os fatores de vulnerabilidade para a agressão, mas também a sua análise do ponto de vista sócio ecológico. 0 desenho de programas que considerem um largo espetro de comportamentos agressivos, poderá ser mais efetivo no combate à agressão entre pares, inclusive no combate ao bullying, pela sobreposição entre estes dois constructos no que respeita aos mecanismos de ajustamento social e aos seus antecedentes explicativos.

\section{REFERÊNCIAS}

Almeida, A., \& Gouveia, P. (2016). Ciberbullying: O papel dos pares, da família e da escola [Cyberbullying: The role of peers, family and school]. In I Patrão \& D Sampaio (Eds.). Dependências online. O Poder das Tecnologias [Online Addictions. The Power of Technology] (1st edition, pp. 75-95). Lisboa: PACTOR.

Álvarez-Garcia, D., Garcia, T., \& Núñez, J. C. (2015). Predictors of school bullying perpetration in adolescence: A systematic review. Aggression and Violent Behavior, 23, 126-136. https://doi.org/10.1016/j.avb.2015.05.007. 
Blakely-McClure, S. J., \& Ostrov, J. M. (2016). Relational aggression, victimization and self-concept: Testing pathways from middle childhood to adolescence. Journal of Youth Adolescence, 45, 376-390. https://doi.org/10.1007/s10964-015-0357-2.

Brank, E., Hoetger, L., \& Hazen, K. (2012). Bullying. Annual Review of Law and Social Science, 8, 213-230. https://doi.org/10.1146/annurev-lawsocsci-102811-173820.

Bronfenbrenner, U. (1994). Ecological models of human development. In T. Husen, \& T. N. Postlethwaite (Eds.), The international encyclopedia of education, (2 ${ }^{\text {nd }}$ ed., pp. 1643-1647). New York: Elsevier Sciences.

Bronfenbrenner, U., \& Morris, P. (1998). The ecology of developmental processes. In W. Damon (Series Ed.) \& R.M. Lerner (Vol. Ed.), Handbook of child psychology Vol. 1. Theoretical models of human development ( $5^{\text {th }}$ ed., pp. 993-1028). New York: Wiley.

Brown, E. C., Low, S., Smith, B. H., \& Haggerty, K. P. (2011). Outcomes from a school- randomized controlled trial of STEPS to RESPECT: A bullying prevention program. School Psychology Review, $40(3), 423-443$.

Bushman, B. J., \& Huesmann, L. R. (2010). Aggression. In S. T. Fiske, D. T. Gilbert, \& G. Lindzey (Eds.), Handbook of social psychology ( $5^{\text {th }}$ ed., pp. 833-863). New York: John Wiley \& Sons.

Card, N. A., \& Little, T. D. (2006). Proactive and reactive aggression in childhood and adolescence: A metaanalysis of differential relational with psychological adjustment. International Journal of Behavioral Development, 30, 466-480. https://doi.org/10.1177/0165025406071904.

Card, N. A., Stucky, B. D., Sawalani, G. M., \& Little, T. D. (2008). Direct and indirect aggression during childhood and adolescence: A meta-analytic review of gender differences, intercorrelations, and relations to maladjustment. Child Development, 79, 1185-1229. https://doi.org/10.1111/j.14678624.2008.01184.x.

Chang, F., Lee, C., Chiu, C., Hsi, W., Huang, T., \& Pan, Y. (2013). Relationships among cyberbullying, school bullying, and mental health in Taiwanese adolescents. Journal of School Health, 83, 454-462. https://doi.org/10.1111/josh.12050.

Cohen, J. (2009). Transforming school climate: Educational and psychoanalytic perspectives. An introduction to a special issue on school climate. Schools: Studies in Education, 6(1), 99-103. https://doi.org/10.1086/597659

Cook, C. R., Williams, K. R., Guerra, N. G., Kim, T. E., \& Sadek, S. (2010). Predictors of bullying and victimization in childhood and adolescence: A meta-analytic investigation. School Psychology Quarterly, 25, 65-83 https://doi.org/10.1037/a0020149.

Copeland-Linder, N., Lambert, S. F., \& Ialongo, N. S. (2010). Community violence, protective factors, and adolescent mental health: A profile analysis. Journal of Clinical Child and Adolescent Psychology, 39, 176-186. https://doi.org/10.1080/15374410903532601.

Crick, N. R., \& Dodge, K. A. (1994). A review and reformulation of social information-processing mechanisms in children's social adjustment. Psychological Bulletin, 115, 74-101. https://doi.org/10.1037/0033-2909.115.1.74.

Crick, N. R., \& Dodge, K. A. (1996). Social-information processing mechanisms in reactive and proactive aggression. Child Development, 67, 993-1002. https://doi.org/10.2307/1131875.

Duncan, R. D. (2004). The impact of family relationships on school bullies and victim. In D. L. Espelage, \& S. M. Swearer (Eds.), Bullying in American schools: A social-ecological perspective on prevention and intervention (pp. 227-244). Mahwah, N. J.: Lawrence Erlbaum Associates, Publishers.

Durlak, J. A., Weissberg, R. P., Dymnicki, A. B., Taylor, R. D., \& Schelliger, K. B. (2011). The Impact of Enhancing Students' Social and Emotional Learning: A Meta-Analysis of School-Based Universal Interventions. Child Development, 82, 405-432. https://doi.org/10.1111/j.14678624.2010.01564.x.

Eisenstein, E. (2005). Adolescência: definições, conceitos e critérios. Adolescência e Saúde, 2(2), 6-7.

Espelage, D. L., \& Swearer, S. (2003). Research on school bullying and victimization: What have we learned and where do we go from here? School Psychology Review, 32(3), 365-383.

Espelage, D. L., Mebane, S. E., \& Swearer, S. M. (2004). Gender differences in bullying: Moving beyond mean level differences. In D. L. Espelage, \& S. M. Swearer (Eds.), Bullying in American schools: $A$ social-ecological perspective on prevention and intervention (pp. 15-35). Mahwah, NJ: Lawrence Erlbaum Associates.

Espelage, D. L., Polanin, J. R., \& Low, S. K. (2014). Teacher and staff perceptions of school environment as predictors of student aggression, victimization, and willingness to intervene in bullying situations. School Psychology Quarterly, 29, 287-305. https://doi.org/10.1037/spq0000072. 
Espelage, D., \& Horne, A. (2008). School violence and bullying prevention: From re- search based explanations to empirically based solutions. In S. Brown, \& R. Lent (Eds.), Handbook of Counselling Psychology (4th ed., pp. 588-606). Hoboken, NJ: John Wiley and Sons.

Farmer, T. W., Petrin, R. A., Robertson, D. L., Fraser, M. W., Hall, C. M., Day, S. H., \& Dajsman, K. (2010). Peer relations of bullies, bully-victims, and victims: The two social worlds of bullying in second-grade classrooms. The Elementary School Journal, 110, 364-392. https://doi.org/10.1086/648983.

Feigenberg, L.F., Watts, C.L., \& Buckner, J.C. (2010). The School Mental Health Capacity Instrument: Development of an assessment and consultation tool. School Mental Health, 2, 142-154. https://doi.org/10.1007/s12310-010-9041-6.

Ferráns, S. D., \& Selman, R. L. (2014). How student's perceptions of the school climate influence their choice to upstand, bystand, or join perpetrators of bullying. Harvard Educational Review, 84(2), 162-187. https://doi.org/10.17763/haer.84.2.h4883134101651mm

Ferráns, S. D., Selman, R. L., \& Feigenberg, L. F. (2012). Rules of the culture and personal needs: witness' decision-making process to deal with situations of bullying in middle school. Harvard Educational Review, 82(4), 445-470. https://doi.org/10.17763/haer.82.4.4u5v1n8q67332v03

Fite, P. J., Rathert, J., Colder, C. R., Lochman, J. E., \& Wells, K. C. (2012). Proactive and reactive aggression. In R. J. R. Levesque (Ed.), Encyclopedia of Adolescence (pp. 2164- 2170). New York, NY: Springer.

Fite, P. J., Stauffacher, K., Ostrov, J. M., \& Colder, C. R. (2008). Replication and extension of Little et al.'s (2003) forms and functions of aggression measure. International Journal of Behavioral Development, 32, 238-242. https://doi.org/10.1177/0165025408089273.

Fraser, M., Kirby, L. D., \& Smokowski, P. R. (2004). Risk and resilience in childhood. In M. Fraser (Ed.), Risk and resilience in childhood: An ecological perspective (pp. 13-66). Washington, DC: NASW Press.

Giovazolias, T., Kourkoutas, E., Mitsopoulou, E., \& Georgiadi, M. (2010). The relatioship between perceived school climate and the prevalence of bullying behavior in Greek schools: implications for preventive inclusive strategies. Procedia Social and Behavioral Sciences, 5, 2208-2215. https://doi.org/10.1016/j.sbspro.2010.07.437.

Gouveia, P., Leal, I., \& Cardoso, J. (2015). Contributos para a Adaptação e Aferição de duas medidas de Suporte Social. Psicologia, Saúde \& Doenças, 16, 386-391. https://doi.org/10.15309/15psd160309.

Griffin, R. S., \& Gross, A. M. (2004). Childhood bullying: Current empirical findings and future directions for research. Aggression and Violent Behavior, 9, 379-400. https://doi.org/10.1542/peds.20052509.

Hawley, P. H., Little, T. D., \& Card, N. A. (2008). The myth of the alpha male: A new look at dominance related beliefs and behaviors among adolescent males and females. International Journal of Behavioral Development, 32, 76-88. https://doi.org/10.1177/0165025407084054.

Hawley, P., \& Vaughn, B. (2003). Aggression and adaptive functioning: The bright side to bad behavior. Merrill-Palmer Quarterly, 49, 239-42. https://doi.org/10.1353/mpq.2003.0012.

Holt, M. K., \& Espelage, D. L. (2007). Perceived social support among bullies, victims, and bully-victims. Journal of Youth and Adolescence, 36, 984-994. https://doi.org/10.1007/s10964-006-9153-3.

Hong, J. S., \& Espelage, D. L. (2012). A review of research on bullying and peer victimization in school: An ecological system analysis. Aggression and Violent Behavior, 17, 311-322. https://doi.org/10.1016/j.avb.2012.03.003.

Kasen, S., Johnson, J. G., Chen, H., Crawford, T. N., \& Cohen, P. (2011). School climate and changes in personality disorder symptom trajectories related to bullying: A prospective study. In D. L. Espelage \& S. M. Swearer (Eds.). Bullying in North American Schools (2nd ed., pp.187-210). New York: Routledge.

Kendrick, K., Jutengren, G., \& Stattin, H. (2012). The protective role of supportive bullying perpetration and victimization. Journal of Adolescence, 35, 1069-1080. https://doi.org/10.1016/j.adolescence.2012.02.014.

Larochette, A., Murphy, A. N., \& Craig, W. M. (2010). Racial bullying and victimization in Canadian schoolaged children: Individual and school level effects. School Psychology International, 31, 389-408. https://doi.org/10.1177/0143034310377150.

LaRusso, M., \& Selman, R. (2011). Early adolescent health risk behaviors, conflict resolution strategies, and school climate. Journal of Applied Development Psychology, 32(6), 354-362.

Lee, C. (2010). Personal and interpersonal correlates of bullying behaviors among Korean middle school students. Journal of Interpersonal Violence, $25, \quad 152-176$. https://doi.org/10.1177/088626050832912.

Li, X., Bian, C., Chen, Y., Huang, J., Ma, Y., Tang, L., Yan, Q., Ye, X., Jie Tang, J., \& Yu, Y. (2015). Indirect aggression and parental attachment in early adolescence: Examining the role of perspective taking 
and empathetic concern. Personality and Individual Differences, 86, 499-503. https://doi.org/10.1016/j.paid.2015.07.008.

Little, T. D., Brauner, J., Jones, S. M., Nock, M. K., \& Hawley, P. H. (2003). Rethinking aggression: A typological examination of the functions of aggression. Merrill-Palmer Quarterly, 49, 343- 369. https://doi.org/10.1353/mpq.2003.0014.

Little, T. D., Jones, S. M., Henrich, C. C., \& Hawley, P. H. (2003). Disentangling the "whys" from the "whats" of aggressive behavior. International Journal of Behavioral Development, 27, 122-133. https://doi.org/10.1080/01650250244000128.

Loflin, D. C., \& Barry, C. T. (2016). 'You can't sit with us:' Gender and the differential roles of social intelligence and peer status in adolescent relational aggression. Personality and Individual Differences, 91, 22-26. https://doi.org/10.1016/j.paid.2015.11.048.

López, E. E., Pérez, S. M., Ochoa, G. M., \& Ruiz, D. M. (2008). Adolescent aggression: Effects of gender and family and school environments. Journal of Adolescence, 31, 433- 450. https://doi.org/10.1016/j.adolescence.2007.09.007.

Marsh, L., McGee, R., \& Williams, S. (2014). School Climate and Aggression among New Zealand High School Students. New Zealand Journal of Psychology, 43(1),28-37.

Matjasko, J. L., Needham, B. L., Grunden, L. N., \& Feldman, A. (2010). Violent victimization and perpetration during adolescence: developmental stage dependent ecological models. Journal of Youth and Adolescence, 39, 1053-1066. https://doi.org/10.1007/s10964-010-9508-7.

Moretti, M. M., Catchpole, R. E. H., \& Odgers, C. (2005). The dark side of girlhood: Recent trends, risk factors, and trajectories to aggression and violence. Canadian Child and Adolescent Psychiatry Review, 14, 21-25.

Moretti, M. M., Holland, R., \& McKay, S. (2001). Self-other representations and relational and overt aggression in adolescent girls and boys. Behavioral Sciences and the Law, 19, 109-126. https://doi.org/10.1002/bsl.429.

Moscardino, U., Fabia, S.S., Capello, F., \& Altoe, G. (2010). Social support, sense of community, collectivistic values, and depressive symptoms in adolescent survivors of the 2004 Beslan terrorist attack, Social Science \& Medicine, 70(1), 27-34.

Musito, G., \& García, J. (2004). Consecuencias de la socialización familiar en la cultura española. Psicothema, 16(2), 288-293.

Ojanen, T., Grönroos, M., \& Salmivalli, C. (2005). An interpersonal circumplex model of children's social goals: Links with peer-reported behavior and sociometric status. Developmental Psychology, 41, 699-710. https://doi.org/10.1037/0012-1649.41.5.699.

Olweus, D. (1978). Aggression in school: bullies and whipping boys. Washington, DC: Hemisphere.

Olweus, D. (1993). Bullying at school: What we know and what we can do. Malden, MA: Blackwell Publishers.

Orpinas, P., Horne, A. M., \& Staniszewski, D. (2003). School bullying: Changing the problem by changing the school. School Psychology Review, 32(3), 431-444.

Ostrov, J. M. (2008). Forms of aggression and peer victimization during early childhood: A short-term longitudinal study. Journal of Abnormal Child Psychology, 36, 311-322. https://doi.org/10.1007/s10802-007-9179-3.

Ostrov, J. M. (2010). Prospective associations between peer victimization and aggression. Child Development, 81, 1670-1677. https://doi.org/10.1111/j.1467-8624.2010.01501.x.

Palacios, D., \& Berger, C. (2016). What is popular? Distinguishing bullying and aggression as status correlates within specific peer normative contexts. Psicologia: Reflexão e Crítica, 29, 1-9. https://doi.org/10.1186/s41155-016-0031-y.

Pellegrini, A. D., \& Bartini, M. (2000). A longitudinal study of bullying, victimization, and peer affiliation during the transition from primary school to middle school. American Educational Research Journal, 37(3), 699-725. https://doi.org/10.2307/1163486

Pinheiro, M. R., \& Ferreira, J. A. (2002). O questionário de suporte social: adaptação e validação portuguesa do social support questionnaire (SSQ6). Psychologica,30, 315-333.

Pokhrel, P., Sussman, S., Black, D., \& Sun, P. (2010). Peer Group Self-Identification as a Predictor of Relational and Physical Aggression Among High School Students. Journal of School Health, 80, 249258. https://doi.org/10.1111/j.1746-1561.2010.00498.x.

Prinstein, M. J., Boergers, J., \& Venberg, E. M. (2001). Overt and relational aggression in adolescents: Social-psychological adjustment of aggressors and victims. Journal of Clinical Child Psychology, 30, 479-491. https://doi.org/10.1207/S15374424JCCP3004_05. 
Procidano, M. E., \& Heller, K. (1983). Measures of Perceived Social Support from Friends and from Family: Three Validation Studies. American Journal of Community Psychology, 11, 1-24. https://doi.org/10.1007/BF00898416.

Prodocimo, E., Cerezo, F., \& Arense, J. J. (2014). Bullying: Family socio-situation as risk or protective factors. Behavioral Psychology/Psicología Conductual, 22(2), 345-359.

Rodkin, P. C. R., Espelage, D. L., \& Hanish, L. D. (2015). A relational framework for understanding bullying. Developmental antecedents and outcomes. American Psychologist, 70, 311-321. https://doi.org/10.1037/a0038658.

Rodkin, P. C., Farmer, T. W., Pearl, R., \& Acker, R. V. (2006). They're cool: Social status and peer group supports for aggressive boys and girls. Social Devevelopment, 15, 175-204. https://doi.org/10.1046/j.1467-9507.2006.00336.x.

Rose, A., Swenson, L., \& Waller. E. (2004). Overt and relational aggression and perceived popularity: Developmental differences in concurrent and prospective relations. Developmental Psycholog, 40, 378-87. https://doi.org/10.1037/0012-1649.40.3.378.

Ross, S. W., \& Horner, R. H. (2009). Bully prevention in positive behavior support. Journal of Applied Behavior Analysis, 42, 747-759. https://doi.org/10.1901/jaba.2009.42-747.

Salmivalli, C. (2010). Bullying and the peer group: A review. Aggression and Violent Behavior, 15, 112-20. https://doi.org/10.1016/j.avb.2009.08.007.

Sarason, I. G., Levine, H. M., Basham, R. B., \& Sarason, B. R. (1983). Assessing social support: The social support questionnaire. Journal of Personality and Social Psychology, 44, 127-130. https://doi.org/10.1037/0022-3514.44.1.127.

Scherman, V. (2005). School Climate Instrument: A Pilot Study in Pretoria and Environs. (Master Dissertation), Faculty of Humanities of the University of Pretoria, Pretoria.

Schwartz, D., McFadyen-Ketchum, S. A., Dodge, K. A., Pettit, G. S., \& Bates, J. E. (1998). Peer group victimization as a predictor of children's behavior problems at home and in school. Development and Psychopathology, 10, 87-99. https://doi.org/10.1017/S095457949800131X.

Seeds, P. M., Harkness, K. L., \& Quilty, L. C. (2010). Parental Maltreatment, Bullyingisepiand Adolescent Depression: Evidence for the Mediating Role of Perceived Social Support. Journal of Clinical Child \& Adolescent Psychology, 39, 681-692. https://doi.org/10.1080/15374416.2010.501289.

Sentse, M., Scholte, R., Salmivalli, C., \& Voeten, M. (2007). Person group-dissimilarity in involvement in bullying and its relation with social status. Journal of Abnormal Child Psychology, 35, 1009-1019. https://doi.org/10.1007/s10802-007-9150-3.

Sijtsema, J. J., Ojanen, T., Veenstra, R., Lindenberg, S., Hawley, P. H., \& Little, T. D. (2010). Forms and functions of aggression on adolescent friendship selection and influence: A longitudinal social network analysis. Social Development, 19, 515-534. https://doi.org/10.1111/j.14679507.2009.00566.x.

Smack, A. J., Kushner, S. C., \& Tackett, J. L. (2015). Child Personality Moderates Associations Between Parenting and Relational and Physical Aggression. Journal of Aggression, Maltreatment \& Trauma, 24, 845-862, https://doi.org/10.1080/10926771.2015.1062450.

Stefanek, E., Strohmeier, D., Van de Schoot, R., \& Spiel, C. (2011). Bullying and victimization in ethnically diverse schools: Risk and protective factors on the individual and class level. International Journal of Developmental Science, 5, 73-84. https://doi.org/10.3233/DEV- 2011-11073.

Swearer, S. M., \& Hymel, S. (2015). Understanding the Psychology of Bullying: Moving toward a socialecological diathesis-stress model. American Psychologist, 70, 344-353. https://doi.org/10.1037/a0038929.

Swearer, S. M., Espelage, D. L., \& Napolitano, S. A. (2009). Bullying prevention and intervention: Realistic strategies for schools. New York, NY: Guilford Press.

Tippett, N., Wolke, D., \& Platt, L. (2013). Ethnicity and bullying involvement in a national UK youth sample. Journal of Adolescence, 36, 639-649. https://doi.org/10.1016/j.adolescence.2013.03.013.

Tochigi, M., Nishida, A., Shimodera, S., Oshima, N., Inoue, K., Okazaki, Y., et al. (2012). Irregular bedtime and nocturnal cellular phone usage as risk factors for being involved in bullying: A cross-sectional survey of Japanese adolescents. PLoS One, 7, e45736. https://doi.org/10. 1371/journal.pone.0045736.

Ttofi, M. M., \& Farrington, D. P. (2011). Effectiveness of school based programs to reduce bullying: A systematic and meta-analytic review. Journal of Experimental Criminology, 7, 27-56. https://doi.org/10.1007/s11292-010-9109-1.

Vaillancourt, T., McDougall, P., Hymel, S., Krygsman, A., Miller, J., Stiver, K., \& Davis, C. (2008). Bullying: Are researchers and children/youth talking about the same thing? International Journal of Behavioral Development, 32, 486-495 [S: 
Varjas, K., Henrich, C. C., \& Meyers, J. (2009). Urban middle school students' perceptions of bullying, cyberbullying, and school safety. Journal of School Violence, 8, 159-176. https://doi.org/10.1080/15388220802074165.

Vitaro, F., \& Brendgen, M. (2005). Proactive and reactive aggression: A developmental perspective. In R. E. Tremblay, W. W. Hartup, \& J. Archer (Eds.), Developmental origins of aggression (pp. 178-201). New York, NY: Guilford Press.

Vitaro, F., \& Brendgen, M. (2011). Subtypes of aggressive behaviors: Etiologies, development, and consequences. In T. Bliesner, A. Beelman \& M. Stemmler (Eds.), Antisocial Behavior and Crime: Contributions of Theory and Evaluation Research in Prevention and Intervention (pp. 17-38). Goettingen, Germany: Hogrefe.

Williams, K. R., \& Guerra, N. G. (2011). Perceptions of collective efficacy and bullying perpetration in schools. Social Problems, 58(1), 126-143. https://doi.org/10.1525/sp.2011.58.1.126

Williford, A., \& DePaolis, K. J. (2012). Identifying Predictors of Instrumental and Reactive Aggression Among Low-Income Minority Adolescent Girls. Journal of the Society for Social Work and Research, 3, 145-161. https://doi.org/10.5243/jsswr.2012.10.

Wilson, S. J., \& Lipsey, M. W. (2007). School-Based Interventions for Aggressive and Disruptive Behavior. Update of a Meta-Analysis. American Journal of Preventive Medicine, 33, S130-S143. https://doi.org/10.1016/j.amepre.2007.04.011.

Wright, J. C., Giammarino, M., \& Parad, H. W. (1986). Social status in small groups: individual-group similarity and the social "misfit". Journal of Personality and Social Psychology, 50(3), 523-536. https://doi.org/10.1037/0022-3514.50.3.523

Xu, Y., \& Zhang, Z. (2008). Distinguishing proactive and reactive aggression in Chinese children. Journal of Abnormal Child Psychology, 36, 539-552. https://doi.org/10.1007/s10802-007-9198-0.

Historial do artigo

Recebido 04/03/2016

Aceite $\quad 09 / 10 / 2017$

Publicado 11/2017 
Intervenção: Preditores de bullying e agressão

Está página encontra-se propositadamente em branco 